\title{
Synergistic Effects of Lifetime Psychiatric Disorders on Suicidal Ideation Among Blacks in the USA
}

\author{
Shervin Assari
}

Received: 20 October 2013 / Revised: 2 June 2014 / Accepted: 23 July 2014 /Published online: 19 August 2014

(C) W. Montague Cobb-NMA Health Institute 2014

\begin{abstract}
Purpose In this study, we aimed to investigate the synergistic effects of lifetime psychiatric disorders including general anxiety disorder (GAD), major depressive disorder (MDD), and drug abuse disorder (DAD) on serious suicidal thoughts among a nationally representative sample of Blacks in the USA.

Methods For this study, we used data of 5,181 Black (3,570 African-American and 1,621 Caribbean Black) adults who participated in the National Survey of American Life (NSAL), 2001-2003. Three lifetime psychiatric disorders (i.e., MDD, $\mathrm{GAD}$, and $\mathrm{DAD}$ ) were considered as independent variables. Lifetime serious suicidal ideation was considered as the dependent variable. Age, gender, ethnicity, education, employment, marital status, and region were control variables. Logistic regression was used to determine separate, additive, and synergistic effects of GAD, MDD, and DAD on serious suicidal thoughts. Results Individuals with comorbid GAD and MDD [odds ratio $(\mathrm{OR})=3.61$, $95 \%$ confidence interval $(\mathrm{CI})=1.26$ 10.33], GAD and DAD (OR=3.22, $95 \% \mathrm{CI}=1.05-9.85)$, and MDD and DAD $(\mathrm{OR}=2.25,95 \% \mathrm{CI}=1.16-4.35)$ were at highest risk of suicidal ideation. In the absence of GAD and MDD, DAD was associated with higher odds of suicidal ideation $(\mathrm{OR}=3.55,95 \% \mathrm{CI}=2.15-5.87)$; however, in the absence of DAD, neither GAD nor MDD was associated with
\end{abstract}

S. Assari $(\bowtie)$

Center for Research on Ethnicity, Culture, and Health (CRECH), University of Michigan School of Public Health, 1415 Washington Heights, 2847-SPH I, Ann Arbor, MI 48109-2029, USA

e-mail: assari@umich.edu

S. Assari

Department of Health Behavior and Health Education, University of Michigan School of Public Health, 1415 Washington Heights, 2847-SPH I, Ann Arbor, MI 48109-2029, USA

S. Assari

Department of Psychiatry, School of Medicine, University of Michigan, 4250 Plymouth Rd, Ann Arbor, MI 48105, USA suicidal ideation. Gender also modified the synergistic effects of GAD, MDD, and DAD on suicidal ideation.

Conclusions Based on our study, GAD, MDD, and DAD have synergistic effects on suicidal thoughts among Blacks. Results may have implications for the reduction of suicide due to psychiatric disorders among Blacks.

Keywords Anxiety $\cdot$ Depression $\cdot$ Drug use $\cdot$ Blacks . Ethnicity $\cdot$ Suicidal ideation
Abbreviations
NSAL National Survey of American Life
DSM-IV Diagnostic and Statistical Manual of Mental
Disorders, Fourth Edition
WMH- World Mental Health Composite International
CIDI Diagnostic Interview
GAD General anxiety disorder
MDD Major depressive disorder
DAD Drug abuse disorder

\section{Introduction}

A considerable proportion of individuals who think about, attempt, or commit suicide endorse criteria for at least one psychiatric disorder [1-4]. A prior psychiatric disorder is present in almost $50 \%$ of those with a suicide ideation and in $65 \%$ of those with an attempt [5]. Research over several decades has suggested that psychiatric disorders, most often mood and drug use, are the most important risk factors of suicide and suicidal ideation [6-10]. According to a systematic review, in the industrial world, the role of psychiatric disorders on suicide may be larger than those of social factors [11].

One limitation of the literature on the effect of psychiatric disorders on suicidal ideation and behaviors is that most studies have been limited to bivariate analysis [5]. As psychiatric disorders are highly comorbid [12], many of the observed bivariate 
associations may be confounded by a small number of disorders [5]. There are only few studies, however, decomposing the effect of psychiatric disorders to find particular disorders that independently contribute to suicidal ideation $[5,9]$.

We have enough evidence that psychiatric disorders increase the risk for suicidal thoughts, planning, and attempt [1-11]. We also know that multiple psychiatric disorders may have additive effects on suicide [13]. It is not fully clear, however, if the effects of different psychiatric disorders on suicidal ideation is synergistic or not.

Most studies that have tested a possible synergistic effect between psychiatric disorders on suicidal behaviors have found sub-additive effects of multiple psychiatric disorders on suicidal behaviors $[4,6]$. This finding has been explained by the notion that the additional contribution of a psychiatric disorder to the risk of suicide might be lower in the presence of another psychiatric disorder [9], a phenomenon that has been attributed to the etiologic and phenotypic overlap between different psychiatric disorders [14-16].

Although traditionally, suicide was believed to be a more crucial public health problem for Whites, the suicide rate among Blacks has increased [17, 18]. According to a recent report, Blacks may experience a similar rate of suicide attempts as Whites [19]. As suicide presents itself at a younger age among Black populations, less time is available for prevention of suicide among Blacks [20].

Joe et al. documented that Blacks with psychiatric disorders are eight times more likely to attempt suicide than those without a psychiatric disorder. Presence of a psychiatric disorder also predicts suicide attempts among Blacks who have suicide ideation [21]. Using Cox regression, Assari et al. found a dose-dependent effect of the number of psychiatric disorders on timing of the first serious suicidal ideation among Blacks [13]. In another study, Assari et al. showed that major depressive disorder, general anxiety disorder, posttraumatic stress disorder, drug abuse, and alcohol abuse have additive effects on the risk of suicidal ideation among Black adults [22].

In the current study, we aimed to investigate synergistic effects of lifetime general anxiety disorder (GAD), major depressive disorder (MDD), and drug abuse disorder (DAD) on lifetime suicidal ideation among a nationally representative sample of Blacks in the USA. The study also studied if gender moderates the synergistic effects of lifetime psychiatric disorders on suicidal ideation.

\section{Methods}

With a cross-sectional design, the current study used data of the National Survey of American Life (NSAL), a national household survey of 5,191 Black (3,570 African-American and 1,621 Caribbean Black) adults. African-American samples compose the largest portion of the NSAL and were selected from the 48 contiguous states and included households that contained at least one Black adult. The sample of Caribbean Blacks included 265 samples that were collected from households within the core sample. The remaining Caribbean Black samples were collected from households within geographic areas that had a high Caribbean population (metropolitan areas where Caribbean Blacks composed more than $10 \%$ of the population) $[23,24]$. Methodology of the NSAL has been previously described [23].

\section{Interviews}

About $14 \%$ of the interviews were partially or entirely conducted by telephone, and $86 \%$ of the interviews were conducted face-to-face using computer-assisted interviewing [23].

\section{Interviewer Training}

The Survey Research Center at the University of Michigan had few trained African-American interviewers. Due to methodological decisions to conduct the interviews by racematched community-based interviewers, the NSAL conducted enormous interviewer training and recruitment. The NSAL used extensive and creative strategies to recruit local and indigenous Black interviewers. These strategies included recruiting retired teachers and other community professionals and posting flyers in Black neighborhoods in places frequented by potential interviewers, such as barbershops, hair salons, community centers, and churches. The NSAL held four interviewer training sessions over the course of 14 months. The NSAL trained and hired more than 300 interviewers. Standard interviewer training sessions were slightly modified to make the interviewers more culturally sensitive [23].

\section{Psychiatric Disorders}

Lifetime major depressive disorder, generalized anxiety disorder, and drug abuse were evaluated based on the Diagnostic and Statistical Manual of Mental Disorders, Fourth Edition (DSM-IV). The World Mental Health Composite International Diagnostic Interview (WMH-CIDI) was used for interviewing [24]. The CIDI was applied by trained lay interviewers. Kessler et al. have shown that WMH-CIDI diagnoses are consistent with diagnoses based on a state-of-the-art clinical research diagnostic interview (Structured Clinical Interview for DSM-IV) [25]. 


\section{Lifetime MDD and GAD}

The CIDI is valid for measurement of lifetime MDD and GAD [26]. Clinical reappraisal studies have shown high concordance of CIDI diagnoses with diagnoses made by psychiatrists [27-29]. Investigation of area under the receiver operating characteristic curve (AUC) has shown excellent concordance between CIDI and Structured Clinical Interview (SCID) for DSM-IV diagnoses of MDD and GAD. The prevalence differences between CIDI and SCID are not significant at the optimal conditions [24, 26-29]. The CIDI is also known to provide valid findings for Blacks and their ethnic groups [13, 22].

\section{Lifetime Drug Abuse Disorder}

Drug abuse disorder was assessed using the WMH-CIDI [30]. Diagnoses are based on the DSM-IV (American Psychiatric Association 1994). Responses to the CIDI were used to classify individuals as meeting DSM-IV criteria for lifetime drug abuse disorder or not. Participants were asked about the use and abuse of a list of drugs such as marijuana (hashish), cocaine in any form (powder, crack, free base, coca leaves, or paste), heroin, opium, glue, LSD, peyote, or any other illicit drugs or prescribed medications (tranquilizers, stimulants, pain killers, or other prescription drugs).

\section{Lifetime Serious Suicidal Ideation}

Participants were asked "have you ever seriously thought about suicide?" As with all other questions asked, participants could refuse to answer this question. Other questions related to suicide attempt and plan were also asked but were not included in this study $[13,22]$.

\section{Covariates}

Covariates included age (continuous variable), gender (dichotomous variable), ethnicity (African-Americans versus Caribbean Blacks), education level (continuous variable), marital status (dichotomous variable), employment (three-level categorical variable), and region (the Northeast, Midwest, South, and West). Caribbean Blacks met at least one of the following inclusion criteria: (1) being of West Indian or Caribbean descent, (2) being from a country in the Caribbean region, or (3) having parents or grandparents that were born in a country within the Caribbean region. Other Blacks were considered African-Americans.

\section{Statistical Analysis}

We used Stata 12 to consider complex sample design. Taylor series linearization was used to estimate standard errors. Subpopulation survey logistic regressions were used for all
Table 1 Descriptive statistics of study variables among AfricanAmericans and Caribbean Blacks $(n=5,181)$

\begin{tabular}{|c|c|c|}
\hline Characteristics & $\begin{array}{l}\text { African- } \\
\text { Americans } \\
(N=3,570)\end{array}$ & $\begin{array}{l}\text { Caribbean } \\
\text { Blacks } \\
(N=1,621)\end{array}$ \\
\hline Age, mean (SD) & $42.32(14.49)$ & $40.27(5.77)$ \\
\hline Education, mean (SD) & $12.43(2.23)$ & $12.88(1.01)$ \\
\hline Income, mean (SD) & $36,833(33,068)$ & $47,044(15,190)$ \\
\hline \multicolumn{3}{|l|}{ Gender, $N(\%)$} \\
\hline Male & $1,271(44.02)$ & $643(50.87)$ \\
\hline Female & $2,299(55.97)$ & $978(49.13)$ \\
\hline \multicolumn{3}{|l|}{ Marital status, $N(\%)$} \\
\hline Married/partner & $1,222(41.65)$ & $693(50.15)$ \\
\hline Widowed, separated, divorced & $1,164(26.77)$ & $385(18.93)$ \\
\hline Never married & $1,176(31.57)$ & $543(30.91)$ \\
\hline
\end{tabular}

$S D$ standard deviation

analyses. Multicollinearity between the covariates was ruled out. $P$ values less than 0.05 were considered statistically significant. $P$ values larger than 0.05 but smaller than 0.1 were considered marginally significant.

Table 2 Additive effects of psychiatric disorders (lifetime) on suicidal ideation (lifetime) among Blacks $(n=5,191)$

\begin{tabular}{|c|c|c|c|}
\hline \multirow[b]{2}{*}{ Age } & \multirow{2}{*}{$\frac{\text { Odds ratio }}{0.978}$} & \multicolumn{2}{|c|}{$95 \%$ confidence interval } \\
\hline & & 0.969 & 0.987 \\
\hline \multicolumn{4}{|l|}{ Education $^{\mathrm{a}}$} \\
\hline 12 years & 0.939 & 0.645 & 1.368 \\
\hline $13-15$ years & 0.775 & 0.511 & 1.175 \\
\hline More than 15 years & 0.761 & 0.504 & 1.148 \\
\hline \multicolumn{4}{|l|}{ Employment $^{\mathrm{b}}$} \\
\hline Unemployed & 1.596 & 1.156 & 2.202 \\
\hline Not in labor market & 1.317 & 0.914 & 1.897 \\
\hline \multicolumn{4}{|l|}{ Marital status ${ }^{\mathrm{c}}$} \\
\hline Divorced/separated/widowed & 1.171 & 0.808 & 1.699 \\
\hline Never married & 0.812 & 0.591 & 1.117 \\
\hline \multicolumn{4}{|l|}{ Region $^{\mathrm{d}}$} \\
\hline Midwest & 0.814 & 0.487 & 1.361 \\
\hline South & 0.724 & 0.456 & 1.150 \\
\hline West & 1.035 & 0.423 & 2.527 \\
\hline Female & 1.174 & 0.892 & 1.545 \\
\hline African-American & 1.206 & 0.664 & 2.190 \\
\hline Depression & 4.159 & 3.210 & 5.390 \\
\hline Drug abuse & 2.285 & 1.390 & 3.758 \\
\hline Anxiety & 2.410 & 1.382 & 4.201 \\
\hline Constant & 0.206 & 0.104 & 0.411 \\
\hline
\end{tabular}

Comparisons with italic numbers are significant at 0.05 .

${ }^{\text {a }}$ Reference group=education less than 12 years

${ }^{\mathrm{b}}$ Reference group $=$ employed

${ }^{\mathrm{c}}$ Reference group $=$ married

${ }^{\mathrm{d}}$ Reference group $=$ Northeast 
In the first step, we ran logistic regressions to test the additive effects of psychiatric disorders. In the next step, we fitted logistic regressions with two-by-two interaction terms (between three psychiatric disorders). All main effects were kept in the model, even if not statistically significant. In all models, serious suicide ideation was the main outcome and sociodemographics (i.e., age, gender, ethnicity, education level, employment, marital status, and country region) were control variables.

\section{Results}

Descriptive statistics of the covariates are depicted in Table 1.

Model Without Interactions

Among Blacks, major depressive disorder, general anxiety disorder, and drug abuse were positively associated with lifetime suicidal ideation. Among Black women, major depressive disorder, general anxiety disorder, and drug abuse were associated with lifetime suicidal ideation. Among Black men, major depressive disorder and drug abuse but not general anxiety disorder were associated with lifetime suicidal ideation (Table 2).

Model with Interactions

Among Blacks, drug abuse but not major depressive disorder and general anxiety disorder had main effects on lifetime suicidal ideation. There were significant interactions between drug abuse and anxiety, drug abuse and depression, and anxiety and depression. Among females, the interaction between drug abuse and depression was not significant. Among males, the only nonsignificant interaction was between drug abuse and anxiety (Table 3 ). Synergistic effects of anxiety, depression, and drug abuse among Black men and women are shown in Tables 4 and 5, respectively.

Table 3 Additive effects of psychiatric disorders (lifetime) on suicidal ideation (lifetime) among Black men $(n=1,914)$ and women $(n=2,277)$

\begin{tabular}{|c|c|c|c|c|c|c|}
\hline & Women & & & Men & & \\
\hline Age & 0.973 & 0.961 & 0.986 & 0.983 & 0.962 & 1.003 \\
\hline \multicolumn{7}{|l|}{ Education $^{\mathrm{a}}$} \\
\hline 12 years & 0.815 & 0.542 & 1.224 & 1.240 & 0.571 & 2.693 \\
\hline $13-15$ years & 0.703 & 0.436 & 1.135 & 0.982 & 0.418 & 2.309 \\
\hline More than 15 years & 0.435 & 0.249 & 0.760 & 1.487 & 0.603 & 3.671 \\
\hline \multicolumn{7}{|l|}{ Employment $^{\mathrm{b}}$} \\
\hline Unemployed & 1.444 & 0.945 & 2.208 & 1.724 & 0.891 & 3.334 \\
\hline Not in labor market & 1.022 & 0.634 & 1.648 & 1.942 & 1.149 & 3.282 \\
\hline \multicolumn{7}{|l|}{ Marital status ${ }^{\mathrm{c}}$} \\
\hline Divorced/separated/widowed & 0.969 & 0.595 & 1.578 & 1.748 & 0.897 & 3.406 \\
\hline Never married & 0.818 & 0.515 & 1.299 & 0.736 & 0.386 & 1.406 \\
\hline \multicolumn{7}{|l|}{ Region $^{\mathrm{d}}$} \\
\hline Midwest & 0.774 & 0.390 & 1.533 & 0.916 & 0.483 & 1.736 \\
\hline South & 0.631 & 0.344 & 1.155 & 0.901 & 0.515 & 1.575 \\
\hline West & 0.594 & 0.286 & 1.235 & 1.792 & 0.543 & 5.913 \\
\hline \multicolumn{7}{|l|}{ Female } \\
\hline African-American & 1.455 & 0.762 & 2.780 & 0.994 & 0.393 & 2.514 \\
\hline Depression & 3.557 & 2.543 & 4.976 & 5.088 & 3.000 & 8.629 \\
\hline Drug abuse & 2.329 & 1.161 & 4.671 & 2.402 & 1.225 & 4.709 \\
\hline Anxiety & 3.181 & 1.761 & 5.747 & 1.436 & 0.379 & 5.444 \\
\hline Constant & 0.363 & 0.148 & 0.891 & 0.108 & 0.027 & 0.424 \\
\hline
\end{tabular}

Comparisons with italic numbers are significant at 0.05 .

${ }^{\text {a }}$ Reference group $=$ education less than 12 years

${ }^{\mathrm{b}}$ Reference group $=$ employed

${ }^{\mathrm{c}}$ Reference group $=$ married

${ }^{\mathrm{d}}$ Reference group $=$ Northeast 
Table 4 Synergistic effects of psychiatric disorders (lifetime) on suicidal ideation (lifetime) among Blacks $(n=5,191)$

\begin{tabular}{lllc}
\hline & Odds ratio & $95 \%$ confidence interval \\
\hline Age & 0.979 & 0.970 & 0.988 \\
Education $^{\mathrm{a}}$ & & & \\
$\quad$ 12 years & 0.940 & 0.647 & 1.365 \\
$\quad$ 13-15 years & 0.773 & 0.514 & 1.163 \\
$\quad$ More than 15 years & 0.720 & 0.466 & 1.111 \\
Employment & & & \\
$\quad$ Unemployed & & & \\
$\quad$ Not in labor market & 1.568 & 1.121 & 2.192 \\
Marital status & 1.294 & 0.903 & 1.855 \\
$\quad$ Divorced/separated/widowed & 1.121 & 0.777 & 1.616 \\
$\quad$ Never married & 0.808 & 0.592 & 1.104 \\
Region & & & \\
$\quad$ Midwest & & & \\
$\quad$ South & 0.831 & 0.517 & 1.337 \\
$\quad$ West & 0.721 & 0.470 & 1.106 \\
Female & 1.045 & 0.435 & 2.511 \\
African-American & 1.177 & 0.890 & 1.556 \\
Depression & 1.165 & 0.675 & 2.011 \\
Drug abuse & 0.674 & 0.238 & 1.909 \\
Anxiety & 3.547 & 2.146 & 5.862 \\
Anxiety $\times$ Depression & 1.900 & 0.532 & 6.787 \\
Anxiety $\times$ Drug abuse & 3.610 & 1.261 & 10.329 \\
Depression $\times$ Drug abuse & 3.220 & 1.053 & 9.847 \\
Constant & 2.248 & 1.162 & 4.349 \\
\hline & 0.979 & 0.970 & 0.988 \\
\hline
\end{tabular}

Comparisons with italic numbers are significant at 0.05 .

${ }^{\text {a }}$ Reference group $=$ education less than 12 years

${ }^{\mathrm{b}}$ Reference group $=$ employed

${ }^{\mathrm{c}}$ Reference group $=$ married

${ }^{\mathrm{d}}$ Reference group $=$ Northeast

\section{Discussion}

The current study showed synergistic effects of lifetime anxiety, depression, and drug abuse on suicidal ideation among Black adults. Based on our study, serious suicidal thoughts are most common among Blacks who have comorbid anxiety and depression, comorbid anxiety and drug abuse, or comorbid depression and drug abuse. This synergistic effect, however, depends on gender.

Our finding is different from the previously reported subadditive effects, which suggest that the independent contribution to risk for suicide by a psychiatric disorder might be lower in the presence of the second psychiatric disorder [9]. Subadditive risks have been attributed to possible redundancy in risk for suicide with different psychiatric disorders, as different psychiatric disorders have overlap in etiology and phenotype [14-16].
From the long list of risk factors of suicide and suicidal ideation [31-33], psychiatric disorders are possibly the strongest ones [34-36]. Depression predicts suicide ideation [1]. Based on our study, among Black men and women, suicidal ideation is not higher among individuals with depression, when anxiety and drug abuse are not present.

Our findings also suggested that synergistic effects of psychiatric disorders on suicidal thoughts among Blacks may depend on gender. Black men and women who have depression and anxiety and Black men who have depression and drug abuse are at highest risk of suicidal ideation.

Although a dose-dependent effect of the number of psychiatric disorders on suicidal ideation is already known [13, 37-39], the synergistic effect of anxiety, depression, and drug abuse on suicidal ideation of Blacks was not reported before. The current study adds to the current knowledge and suggests that comorbidity between drug abuse, depression, and anxiety produces an effect that is greater than the sum of the individual effects of disorders.

After controlling for anxiety, depression, and drug abuse, ethnicity did not have a residual effect on suicidal ideation. Joe et al. showed that African-Americans are five times more likely to attempt suicide than Caribbean Blacks [40]. Assari et al. showed that Caribbean Blacks and African-Americans differ in the additive effects of psychiatric disorders on risk of lifetime suicidal ideation. Among African-Americans, major depressive disorder, general anxiety disorder, posttraumatic stress disorder, and alcohol abuse disorder were associated with risk of suicidal thoughts; however, among Caribbean Blacks, major depressive disorder and drug abuse disorder were associated with higher odds of suicidal thoughts [22].

Based on the results of the current study, it is not depression-per se- but comorbid depression and anxiety or comorbid depression and drug abuse that are associated with high suicidal ideation among Black adults. As a result, suicide prevention programs should include screening for comorbid anxiety or drug abuse among Blacks with depression. Gender, however, should inform a design of such screening protocols [41]. Comorbid depression and drug abuse among Black men, and comorbid anxiety and drug abuse among Black women are particularly associated with high risk of suicidal ideation.

The current study had a few limitations. Due to crosssectional design, causative associations are not plausible. Moreover, the validity of the single item measure for suicidal ideation is unknown. Suicidal thought is subjected to possible misclassification due to over- or underreporting. In addition, we do not have evidence regarding the validity of diagnoses of anxiety, depression, and drug abuse using the Composite International Diagnostic Interview based on ethnicity and gender of Blacks $[25,30]$.

The current study showed a synergistic effect between $\mathrm{DAD}$ and anxiety and depression on risk of suicidal ideation among Blacks. Findings may have clinical implications for 
Table 5 Synergistic effects of psychiatric disorders (lifetime) on suicidal ideation (lifetime) among men $(n=1,914)$ and women $(n=2,277)$

\begin{tabular}{|c|c|c|c|c|c|c|}
\hline \multirow[b]{3}{*}{ Age } & \multicolumn{3}{|l|}{ Females } & \multicolumn{3}{|l|}{ Males } \\
\hline & \multirow{2}{*}{$\begin{array}{l}\text { Odds ratio } \\
0.974\end{array}$} & \multicolumn{2}{|c|}{$95 \%$ confidence interval } & \multirow{2}{*}{$\begin{array}{l}\text { Odds ratio } \\
0.984\end{array}$} & \multicolumn{2}{|c|}{$95 \%$ confidence interval } \\
\hline & & 0.961 & 0.987 & & 0.964 & 1.005 \\
\hline \multicolumn{7}{|l|}{ Education $^{\mathrm{a}}$} \\
\hline 12 years & 0.820 & 0.542 & 1.240 & 1.225 & 0.572 & 2.626 \\
\hline $13-15$ years & 0.697 & 0.425 & 1.143 & 0.927 & 0.400 & 2.148 \\
\hline More than 15 years & 0.398 & 0.226 & 0.703 & 1.413 & 0.566 & 3.530 \\
\hline \multicolumn{7}{|l|}{ Employment $^{\mathrm{b}}$} \\
\hline Unemployed & 1.433 & 0.927 & 2.217 & 1.656 & 0.821 & 3.341 \\
\hline Not in labor market & 0.997 & 0.633 & 1.571 & 1.908 & 1.110 & 3.277 \\
\hline \multicolumn{7}{|l|}{ Marital status $^{c}$} \\
\hline Divorced/separated/widowed & 0.963 & 0.597 & 1.552 & 1.558 & 0.793 & 3.063 \\
\hline Never married & 0.802 & 0.505 & 1.273 & 0.760 & 0.399 & 1.446 \\
\hline \multicolumn{7}{|l|}{ Region $^{\mathrm{d}}$} \\
\hline Midwest & 0.771 & 0.407 & 1.458 & 0.969 & 0.542 & 1.734 \\
\hline South & 0.618 & 0.345 & 1.105 & 0.929 & 0.558 & 1.549 \\
\hline West & 0.581 & 0.282 & 1.198 & 1.938 & 0.603 & 6.224 \\
\hline \multicolumn{7}{|l|}{ Female gender } \\
\hline African-American & 1.413 & 0.759 & 2.632 & 0.970 & 0.403 & 2.330 \\
\hline Depression & 0.466 & 0.134 & 1.623 & 0.511 & 0.112 & 2.336 \\
\hline Drug abuse & 4.239 & 1.819 & 9.882 & 3.749 & 1.949 & 7.209 \\
\hline Anxiety & 3.984 & 0.473 & 33.524 & 1.784 & 0.233 & 13.647 \\
\hline Anxiety $\times$ Depression & 3.874 & 1.169 & 12.838 & 4.122 & 1.024 & 16.592 \\
\hline Anxiety $\times$ Drug abuse & 1.846 & 0.227 & 14.993 & 2.293 & 0.358 & 14.697 \\
\hline Depression $\times$ Drug abuse & 2.589 & 0.858 & 7.812 & 3.805 & 1.230 & 11.774 \\
\hline Constant & 0.351 & 0.142 & 0.870 & 0.095 & 0.025 & 0.370 \\
\hline
\end{tabular}

Comparisons with italic numbers are significant at 0.05 .

${ }^{\text {a }}$ Reference group $=$ education less than 12 years

${ }^{\mathrm{b}}$ Reference group $=$ employed

${ }^{\mathrm{c}}$ Reference group $=$ married

${ }^{\mathrm{d}}$ Reference group $=$ Northeast

treatment of drug abuse, as suicidal behaviors are a major challenge in the treatment of drug users [42-48] and of other psychiatric disorders [49]. However, suicidal behavior among drug abusers depends on the type of substance they use. There is a well-developed literature on suicidal behaviors of individuals who use or abuse alcohol [50-52], heroin [53-55], opiates [56], and other drugs [57]. The current study, however, did not measure the type of substance being used by the individuals.

Based on our findings, individuals with drug abuse who do not endorse anxiety and depression are still at higher risk of suicidal ideation. Individuals with substance use disorders are at elevated risk for suicidal ideation and suicide attempts [58]. They enter treatment at peaks in depressive symptoms [53]. Research has consistently shown high prevalence of suicidal thoughts and attempts among persons with substance abuse problems who are under treatment [43].
Future research should go beyond Blacks and explore possible ethnic differences in the synergistic effects of psychiatric disorders on suicidal ideation. Other outcomes such as suicidal attempt and the committing of suicide should also be investigated. In addition, as other psychiatric disorders such as bipolar disorder and schizophrenia are associated with suicide, future research should include a wider range of psychiatric disorders. As age of suicide or suicidal ideation is also important, future research should use time-to-event analysis. As drug abuse is a broad condition and the effect of certain drugs on suicidal behaviors may be larger than others, future research should also investigate the type of drugs associated with suicidal outcomes [50-57]. Unfortunately, we could not study the effect of the type of drug due to limitations of the data collected in this survey. Finally, although our study explored risk factors for suicidal ideation, we used the literature on risk factors of suicide and 
suicide attempts, as well. This issue should be acknowledged while our results and discussion are being read and interpreted.

We argue that history about suicidal ideation is needed in any mental health evaluation. Available data do not suggest that asking about suicide will increase the risk of suicide [59]. Evaluation of suicidal ideation is very important. Clinicians should remember that gathering information on this regard is impossible, unless suicidality is directly asked [42].

Although our study suggested that there is a synergistic effect between psychiatric disorders on suicidal ideation among Blacks in the USA, most individuals with suicidal ideation only have one psychiatric disorder. As only a small proportion of individuals meet criteria for multiple psychiatric disorders, we do not suggest screening of the general population for multiple psychiatric disorders. We, however, suggest screening for comorbid conditions among Blacks who have been diagnosed or endorse criteria for depression, anxiety, or drug abuse. Future research should also include psychiatric disorders not included in this study. Research is also needed to understand if ethnicity modifies the complex interaction between psychiatric disorders on suicidal ideation.

To conclude, the current study showed synergistic effects of anxiety, depression, and drug abuse on suicidal thoughts among Black adults. This synergistic effect, however, may differ among Black men and women.

Acknowledgments The National Survey of American Life (NSAL) is supported by the National Institute of Mental Health (NIMH; U01MH57716) with supplemental support from the Office of Behavioral and Social Science Research (OBSSR) and the National Institute on Drug Abuse (NIDA) at the National Institutes of Health (NIH) and the University of Michigan. Data were downloaded from the Interuniversity Consortium for Political and Social Research (ICPSR), Institute for Social Research (ISR), University of Michigan.

Conflict of Interest Shervin Assari declares that he has no conflict of interest.

Informed Consent All procedures followed were in accordance with the ethical standards of the responsible committee on human experimentation (institutional and national) and with the Helsinki Declaration of 1975 , as revised in 2000. Informed consent was obtained from all patients for being included in the study.

\section{References}

1. Nock MK, Hwang I, Sampson N, Kessler RC. Mental disorders, comorbidity, and suicidal behaviors: results from the National Comorbidity Survey Replication. Mol Psychiatry. 2010;15(8): 868-76.

2. Borges G, Nock MK, Kessler RC, Haro Abad JM, Hwang I, Sampson NA, et al. Twelve month prevalence of and risk factors for suicide attempts in the WHO World Mental Health Surveys. J Clin Psychiatry. 2010;71(12):1617-28.
3. Nock MK, Kessler RC. Prevalence of and risk factors for suicide attempts versus suicide gestures: analysis of the National Comorbidity Survey. J Abnorm Psychol. 2006;115:616-23.

4. Flensborg-Madsen T, Knop J, Mortensen EL, Becker U, Sher L, Grønbaek M. Alcohol use disorders increase the risk of completed suicide - irrespective of other psychiatric disorders. A longitudinal cohort study. Psychiatry Res. 2009;167(1-2):123-30.

5. Borges G, Nock MK, Medina-Mora ME, Hwang I, Kessler RC. Psychiatric disorders, comorbidity, and suicidality in Mexico. J Affect Disord. 2010;124(1-2):98-107.

6. Borges G, Angst J, Nock MK, Ruscio AM, Walters EE, Kessler RC. Risk factors for twelve-month suicide attempts in the National Comorbidity Survey Replication (NCS-R). Psychol Med. 2006;36: 1747-57.

7. Nock MK, Kazdin AE, Hiripi E, Kessler RC. Lifetime prevalence, correlates, and persistence of DSM-IV oppositional defiant disorder: results from the National Comorbidity Survey Replication. J Child Psychol Psychiatry. 2007;48:703-13.

8. Borges G, Angs J, Nock MK, Ruscio AM, Kessler RC. Risk factors for the incidence and persistence of suicide-related outcomes: a 10year follow-up study using the National Comorbidity Survey. J Affect Disord. 2008;105:25-33.

9. Nock MK, Hwang I, Sampson N, Kessler RC, Angermeyer M, Beautrais A, et al. Cross-national analysis of the associations among mental disorders and suicidal behavior: findings from the WHO World Mental Health Surveys. PLoS Med. 2009;6:e1000123.

10. Nock MK, Borges G, Bromet EJ, Alonso J, Angermeyer M, Beautrais $\mathrm{A}$, et al. Cross-national prevalence and risk factors for suicidal ideation, plans and attempts. $\mathrm{Br} \mathrm{J}$ Psychiatry. 2008;192:98-105.

11. Li Z, Page A, Martin G, Taylor R. Attributable risk of psychiatric and socio-economic factors for suicide from individual-level, populationbased studies: a systematic review. Soc Sci Med. 2011;72:608-16.

12. Kessler RC, Chiu WT, Demler O, Merikangas KR, Walters EE. Prevalence, severity, and comorbidity of 12-month DSM-IV disorders in the National Comorbidity Survey Replication. Arch Gen Psychiatry. 2005;62:617-27.

13. Assari S, Lankarani MM, Moazen B. Religious beliefs may reduce the negative effect of psychiatric disorders on age of onset of suicidal ideation among Blacks in the United States. Int J Prev Med. 2012;3: 358-64.

14. Zhang Y, Conner KR, Phillips MR. Case-control study in China of risk factors for suicide in men with alcohol use disorders. J Stud Alcohol Drugs. 2012;73(1):15-20.

15. Kendler KS, Aggen SH, Knudsen GP, Røysamb E, Neale MC, Reichborn-Kjennerud $\mathrm{T}$. The structure of genetic and environmental risk factors for syndromal and subsyndromal common DSM-IV axis I and all axis II disorders. Am J Psychol. 2011;168:29-39.

16. Rzhetsky A, Wajngurt D, Park N, Zheng T. Probing genetic overlap among complex human phenotypes. Proc Natl Acad Sci U S A. 2007;104:11694-9.

17. Centers for Disease Control and Prevention (CDC). Suicide among black youths-United States, 1980-1995. MMWR Morb Mortal Wkly Rep. 1998;47:193-6.

18. Griffith EE, Bell CC. Recent trends in suicide and homicide among blacks. JAMA. 1989;262:2265-9.

19. Eaton DK, Kann L, Kinchen S, Ross J, Hawkins J, Harris WA, et al. Youth risk behavior surveillance-United States, 2005. MMWR Surveill Summ. 2006;55:1-108.

20. Garlow SJ, Purselle D, Heninger M. Ethnic differences in patterns of suicide across the life cycle. Am J Psychiatry. 2005;162:319-23.

21. Joe S, Baser RE, Breeden G, Neighbors HW, Jackson JS. Prevalence of and risk factors for lifetime suicide attempts among Blacks in the United States. JAMA. 2006;296:2112-23.

22. Assari S, Moghani Lankarani M, Moghani Lankarani R. Ethnicity modifies the effects of anxiety and drug use on suicidal ideation 
among Black adults in the United States. Int J Prev Med. 2012;3: 358-64.

23. Jackson JS, Torres M, Caldwell CH, Neighbors HW, Nesse RM, Taylor RJ, et al. The National Survey of American Life: a study of racial, ethnic and cultural influences on mental disorders and mental health. Int J Methods Psychiatr Res. 2004;13:196-207.

24. Williams DR, Haile R, González HM, Neighbors H, Baser R, Jackson JS. The mental health of Black Caribbean immigrants: results from the National Survey of American Life. Am J Public Health. 2007;97:52-9.

25. Kessler RC, Abelson J, Demler O, Escobar JI, Gibbon M, Guyer ME, et al. Clinical calibration of DSM-IV diagnoses in the World Mental Health (WMH) version of the World Health Organization (WHO) Composite International Diagnostic Interview (WMHCIDI). Int J Methods Psychiatr Res. 2004;13:122-39.

26. Wittchen HU. Reliability and validity studies of the WHOComposite International Diagnostic Interview (CIDI): a critical review. J Psychiatr Res. 1994;28(1):57-84.

27. Robins LN, Wing J, Wittchen HU, Helzer JE, Babor TF, Burke J, et al. The Composite International Diagnostic Interview. An epidemiologic Instrument suitable for use in conjunction with different diagnostic systems and in different cultures. Arch Gen Psychiatry. 1988;45(12):1069-77.

28. Kessler RC, Wittchen HU, Abelson JM, McGonagle K, Schwarz N, Kendler KS, et al. Methodological studies of the Composite International Diagnostic Interview (CIDI) in the US National Comorbidity Survey (NCS). Int J Methods Psychiatr Res. 1998;7(1):33-55.

29. Kessler RC, Calabrese JR, Farley PA, Gruber MJ, Jewell MA, Katon $\mathrm{W}$, et al. Composite International Diagnostic Interview screening scales for DSM-IV anxiety and mood disorders. Psychol Med. 2013;43(8):1625-37.

30. Kessler RC, Ustün TB. The World Mental Health (WMH) Survey Initiative Version of the World Health Organization (WHO) Composite International Diagnostic Interview (CIDI). Int J Methods Psychiatr Res. 2004;13:93-121.

31. Nordentoft M. Prevention of suicide and attempted suicide in Denmark. Epidemiological studies of suicide and intervention studies in selected risk groups. Dan Med Bull. 2007;54:306-69.

32. Qin P, Agerbo E, Westergård-Nielsen N, Eriksson T, Mortensen PB. Gender differences in risk factors for suicide in Denmark. Br J Psychiatry. 2000;177:546-50.

33. Agerbo E, Nordentoft M, Mortensen PB. Familial, psychiatric, and socioeconomic risk factors for suicide in young people: nested casecontrol study. Br Med J. 2002;325:74.

34. King E. Suicide in the mentally ill. An epidemiological sample and implications for clinicians. Br J Psychiatry. 1994;165:658-63.

35. Alexopoulos GS, Bruce ML, Hull J, Sirey JA, Kakuma T. Clinical determinants of suicidal ideation and behavior in geriatric depression. Arch Gen Psychiatry. 1999;56:1048-53.

36. Legleye S, Beck F, Peretti-Watel P, Chau N, Firdion JM. Suicidal ideation among young French adults: association with occupation, family, sexual activity, personal background and drug use. J Affect Disord. 2010;123:108-15.

37. Mościcki EK, O'Carroll P, Rae DS, Locke BZ, Roy A, Regier DA. Suicide attempts in the epidemiologic catchment area study. Yale J Biol Med. 1988;61:259-68.

38. Lewinsohn PM, Rohde P, Seeley JR. Adolescent suicidal ideation and attempts: prevalence, risk factors, and clinical implications. Clin Psychol Sci Pract. 1996;3:25-46.

39. Petronis KR, Samuels JF, Moscicki EK, Anthony JC. An epidemiologic investigation of potential risk factors for suicide attempts. Soc Psychiatry Psychiatr Epidemiol. 1990;25:193-9.
40. Joe S, Baser RS, Neighbors HW, Caldwell CH, Jackson JS. 12-month and lifetime prevalence of suicide attempts among black adolescents in the National Survey of American Life. J Am Acad Child Adolesc Psychiatry. 2009;48:271-82.

41. Cummings JR, Ponce NA, Mays VM. Comparing racial/ethnic differences in mental health service use among high-need subpopulations across clinical and school-based settings. J Adolesc Health. 2010;46:603-6.

42. U.S. Department of Health and Human Services. Substance Abuse and Mental Health Services Administration Center for Substance Abuse Treatment. Addressing suicidal thoughts and behaviors in substance abuse treatment. A treatment improvement protocol.

43. Ilgen MA, Harris AH, Moos RH, Tiet QQ. Predictors of a suicide attempt one year after entry into substance use disorder treatment. Alcohol Clin Exp Res. 2007;31(4):635-42.

44. Tiet QQ, Byrnes HF, Barnett P, Finney JW. A practical system for monitoring the outcomes of substance use disorder patients. J Subst Abus Treat. 2006;30:337.

45. Tiet QQ, Ilgen MA, Byrnes HF, Moos RH. Suicide attempts among substance use disorder patients: an initial step toward a decision tree for suicide management. Alcohol Clin Exp Res. 2006;30:998-1005.

46. Wines JD, Saitz R, Horton NJ, Lloyd-Travaglini C, Samet JH. Suicidal behavior, drug use and depressive symptoms after detoxification: a 2-year prospective study. Drug Alcohol Depend. 2004;76 Suppl 1:S21.

47. Ilgen MA, Tiet Q, Finney JW, Harris AHS. A recent suicide attempt and the effectiveness of inpatient and outpatient substance use disorder treatment. Alcohol Clin Exp Res. 2005;29:1664-71.

48. Ilgen M, Tiet Q, Moos R. Outcomes of substance use disorder treatment in suicidal and non-suicidal male patients. J Stud Alcohol. 2004;65:643-50.

49. Tiet QQ, Finney JW, Moos RH. Recent sexual abuse, physical abuse, and suicide attempts among male veterans seeking psychiatric treatment. Psychiatr Serv. 2006;57:107-13.

50. Roy A, Lamparski D, DeJong J, Moore V, Linnoila M. Characteristics of alcoholics who attempt suicide. Am J Psychiatry. 1990;147:761-5.

51. Wilcox HC, Conner KR, Caine ED. Association of alcohol and drug use disorders and completed suicide: an empirical review of cohort studies. Drug Alcohol Depend. 2004;76 Suppl 7:S11-9.

52. Berglund M, Ojehagen A. The influence of alcohol drinking and alcohol use disorders on psychiatric disorders and suicidal behavior. Alcohol Clin Exp Res. 1998;22(7 Suppl):333S-45.

53. Ross J, Teesson M, Darke S, Lynskey M, Ali R, Ritter A, et al. The characteristics of heroin users entering treatment: findings from the Australian treatment outcome study (ATOS). Drug Alcohol Rev. 2005; $24: 411-8$

54. Darke S, Ross J. Suicide among heroin users: rates, risk factors and methods. Addiction. 2002;97:1383-94.

55. Darke S, Ross J, Lynskey M, Teesson M. Attempted suicide among entrants to three treatment modalities for heroin dependence in the Australian Treatment Outcome Study (ATOS): prevalence and risk factors. Drug Alcohol Depend. 2004;73:1-10.

56. Roy A. Characteristics of opiate dependent patients who attempt suicide. J Clin Psychiatry. 2002;63:403-7.

57. Johnsson E, Fridell M. Suicide attempts in a cohort of drug abusers: a 5-year follow-up study. Acta Psychiatr Scand. 1997;96:362-6.

58. Kessler RC, Borges G, Walters EE. Prevalence of and risk factors for lifetime suicide attempts in the National Comorbidity Survey. Arch Gen Psychiatry. 1999;56:617-26.

59. Gould MS, Marrocco FA, Kleinman M, Thomas JG, Mostkoff K, Cote J, et al. Evaluating iatrogenic risk of youth suicide screening programs: a randomized controlled trial. JAMA. 2005;293:1635-43. 